\title{
CLINICAL IMPORTANT HEMODYNAMIC CHARACTERISTICS FOR SERIAL STENOSED CORONARY ARTERY
}

\author{
S.I. BERNAD ${ }^{1}$, E.S. BERNAD 2 , A.F. TOTOREAN ${ }^{3}$, M.L. CRAINA ${ }^{2}$ \& I. SARGAN SA $^{2}$ \\ ${ }^{1}$ Romanian Academy-Timisoara Branch, Centre for Fundamental and Advanced Technical Research, Romania \\ 2University of Medicine and Pharmacy "Victor Babes" Timisoara, University Clinic "Bega", Romania \\ ${ }^{3}$ University Politehnica Timisoara, Department of MMUT, Romania
}

\begin{abstract}
Effects of serial stenosis on coronary hemodynamics are investigated in the human right coronary artery (RCA) by blood flow analysis. The 3D reconstruction of the geometry of the stenosed coronary artery uses the multislice computerized tomography serial images method. Results of the numerical analysis present the hemodynamic characteristics of the serial stenosed coronary artery throughout the flow separation, pressure drop and wall shear stress. The pressure loss associated with recirculation region created in the vicinity of each constriction was found to be large. In two stenoses the corresponding pressure gradients are around $30 \mathrm{mmHg}$ and correspond to the stenosis with fractional flow reserve-FFR $<0.7$ (value associated to the severe stenosis). Distal to the stenosis, flow is associated with fluctuations in the wall shear stress and vorticity. Both FFR and CFD analysis help identify intermediate lesions that require intervention and reduce unnecessary procedures with potential complications.
\end{abstract}

Keywords: fractional flow reserve, hemodynamics, pressure drop, right coronary artery, serial stenosis, wall shear stress

\section{INTRODUCTION}

The flow phenomena in the stenotic arteries include asymmetric flow, instabilities, and laminar-toturbulent transition. The unsteady flow in a stenotic artery is also characterized by high pressure and wall shear stress (WSS) in the throat and distal to the stenosis [1, 2]. Significant stenosis produces loss of perfusion pressure and flows to the distal (post stenotic) vascular bed [3]. Energy loss at the stenosis produces a pressure gradient between proximal and distal artery regions $[4,5]$.

Multiple stenoses in diseased vascular bed may occur because of the formation of the primary stenosis that can result in downstream circulation flow. This recirculation zone creates the secondary stenosis. Marques and Westerhof [6], Kangl et al. [7] have carried out experimental studies related to flow dynamics in constricted vessels. They suggested that the flow energy loss due to the presence of the stenoses, which is directly related to the pressure drops across them, increases with the number of stenoses and is not strongly dependent on the spacing between them. Younis and Berger [8] and Damodaran et al. [9] have made 2D steady flow computational analysis of flow in multiple constricted vessels. Johnston et al. [10] presented an assessment of the serial stenosis by summing the value of the resistance of each stenosis. Sabbah and Stein [11] concluded that multiple stenoses produce more resistance to flow than a single stenosis of similar length. Johnston and Kilpatrick [12], Bernad et al. [13] simulated the arterial blood flow in triple smooth stenoses. In order to evaluate the influences of the serial stenosis Bertolotti et al. [14] present evolution of the peak the systolic velocity ratio and pressure drop during the cardiac cycle.

The scope of this paper, is to describe the fundamental aspects of the serial stenosis of the right coronary artery (RCA), and used the results in clinical practice to facilitate decision making in the cardiac catheterization laboratory. 


\section{METHODS}

Hemodynamic flow assessment in coronary arteries is usually performed with intravascular Doppler ultrasound by measuring local velocities [15]. An alternative means for invasive flow measurements is presented by the calculation of models in which blood flow can be virtually simulated, a method that is called computational fluid dynamics (CFD). In fact, several in vitro studies $[6,10,16,17,18]$ have shown that CFD allows reliable physiologic blood flow simulation and measurements of WSS, wall pressure, and mass flow. A detailed hemodynamic evaluation of disturbed flow in the post stenotic region may give additional insight of the progression of atherosclerosis and may have useful clinical value, such as early detection of a highly stenosed artery segment, prediction of future disease progression, and treatment planning

\subsection{Artery reconstruction}

A Somatom Sensation 64 Scanner (Siemens Medical Systems, Erlangen, Germany) was used in non-enhanced spiral scan technique with a slice thickness of $0.75 \mathrm{~mm}$, a table feed of $1 \mathrm{~mm} / \mathrm{s}$, and an increment of $2 \mathrm{~mm}$ (Fig. 2). Data corresponding to the investigated patient is presented in Table 1. The CA and the spiral CT investigation detected a multiple severe right coronary artery (RCA) stenosis (Fig. 1). According to the NASCET (North American Symptomatic Carotid Endarterectomy Trial) [19] and ECST (European Carotid Surgery Trial) [20] method of stenosis classification, the stenoses severity is illustrated in Table 2 .

Figure 1 shows the reconstructed lumen geometry of the RCA viewed from the epicardial, and pericardial sides. The lumen inlet diameter of the RCA was $3.8 \mathrm{~mm}$. The RCA is modeled to be $52 \mathrm{~mm}$ in length with variable diameters, depending on the stenosis severity. Data corresponding to the reconstructed RCA is presented in Table 2.

For meshing procedure, the commercial grid generation software, GAMBIT 2.4.6 (Ansys FLUENT, ANSYS, Inc.) was used [21]. Numerical simulations were carried out varying the number of mesh elements in the computational domain. The accuracy of the simulation results was then improved by employing a finer mesh that contained around 1,600,000 elements.

Table 1: Preoperative patient characteristics.

\begin{tabular}{ll}
\hline Variables & Value \\
\hline Mean age & 44 \\
Gender (M/F) & Male \\
History of MI & No \\
Previous PTCA & No \\
Renal insufficiency & No \\
Cardiovascular risk factor & \\
Hypertension & Yes \\
Diabetes & No \\
Smoking & Yes \\
Obesity & Moderate \\
Angiographic data & \\
RCA stenosis & Multiple/Severe \\
\hline
\end{tabular}

$\mathrm{MI}=$ myocardial infarction, $\mathrm{PTCA}=$ percutaneous transluminal coronary angioplasty, $\mathrm{RCA}=$ right coronary artery. 


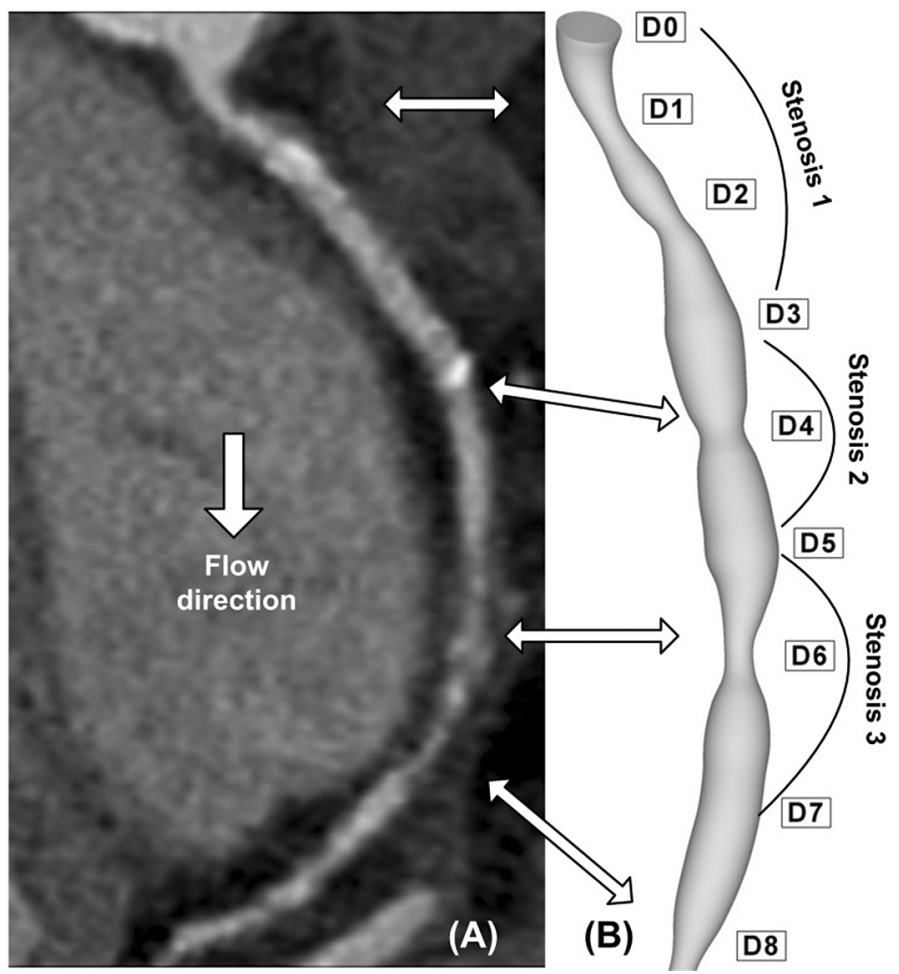

Figure 1: Patient-specific right coronary artery (RCA); (A) Orthogonal-curved multiplanar reconstructions image which indicates a multiple coronary stenosis at the RCA; (B) Geometry reconstruction epicardial side view.

Table 2: RCA stenosis severity.

\begin{tabular}{lccccl}
\hline Seference & $\begin{array}{c}\text { Stenosis } \\
\text { minimal } \\
\text { diameter } \\
{[\mathrm{mm}]}\end{array}$ & $\begin{array}{c}\text { Diameter } \\
\text { reduction } \\
\text { percentage } \\
{[\%]}\end{array}$ & $\begin{array}{c}\text { Area } \\
\text { reduction } \\
\text { percentage } \\
{[\%]}\end{array}$ & $\begin{array}{c}\text { Stenoses } \\
\text { severity }\end{array}$ \\
\hline ST1 & 3.8 & 1.76 & 54 & 77 & Severe (70-99\%) \\
ST2 & 3.6 & 2.6 & 28 & 53 & Moderate (30-69\%) \\
ST3 & 3.6 & 1.68 & 53 & 80 & Severe (70-99\%) \\
\hline
\end{tabular}

The percentage diameter reduction for a circular stenosis is $1-\mathrm{d} / \mathrm{D}$, where $\mathrm{d}$ is the diameter of the lumen and $\mathrm{D}$ the diameter of the non occluded artery.

\subsection{Computational fluid dynamics}

The blood is assumed to be incompressible having dynamic viscosity $(\mu)$ of 0.00408 Pas and a density ( $\rho$ ) of $1050 \mathrm{~kg} / \mathrm{m}^{3}$. Johnston et al. [10] compared the effects of different blood viscosity models on the WSS distributions in the RCA during the cardiac cycle. Their study showed that the use of a 


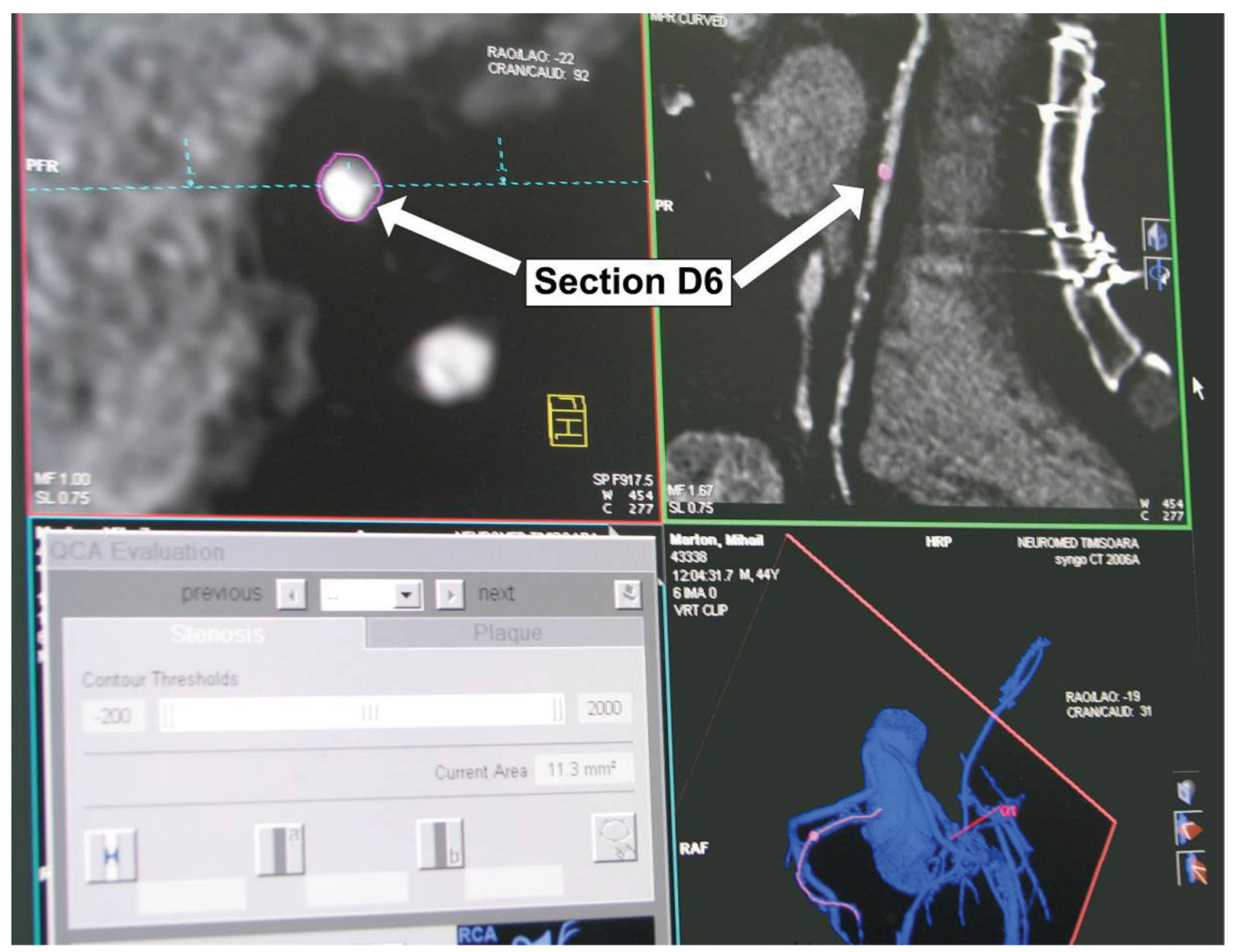

Figure 2: Physiologically realistic geometry measurements using CT image techniques. Area measurements of the stenosed section. For the position of section D6 see Fig. 1.

Newtonian blood model is a reasonably good approximation when studying the WSS distribution for transient blood flow in arteries.

A large number of studies computational [22-27] of the hemodynamics in diseased arteries exhibit disordered and turbulent flows in such vessels. Turbulence can significantly affect the pressure and shear stress downstream of the stenosis [28].

Present simulations carried out over a range of Reynolds numbers (based on the centerline temporally averaged streamwise velocity and the bypass radius) from 250 to 1200 . The maximum Reynolds number during the cycle was about 1118 .

The blood flow is simulated with the commercial CFD FLUENT 6.3 package [21], parallelized across eight $3.2 \mathrm{GHz}$ Intel processors of a TYANPSC T-650 Rx (Tyan Computer Corporation, Taiwan, parallel computing machine with sixteen $3.2 \mathrm{GHz}$ processors) is used in order to perform the numerical analysis.

The walls were taken as solid and stiff, and a zero-velocity boundary condition was assumed for the walls, corresponding to a no-slip condition. As usually adopted by most previous investigations, the distension of the blood vessel wall is neglected. Zeng et al. [30] investigated a disease-free RCA with in vivo flow waveform, physiological realistic compliance data, and artery motions. In conclusion, coronary compliance has little influence on hemodynamic parameter wall shear stress (WSS). The flow velocity profile reflects, the physiologically pulsating biphasic blood flow from the ascending aorta into the coronary arteries [31] (Fig. 3A). The TECPLOT (Tecplot, Inc., 

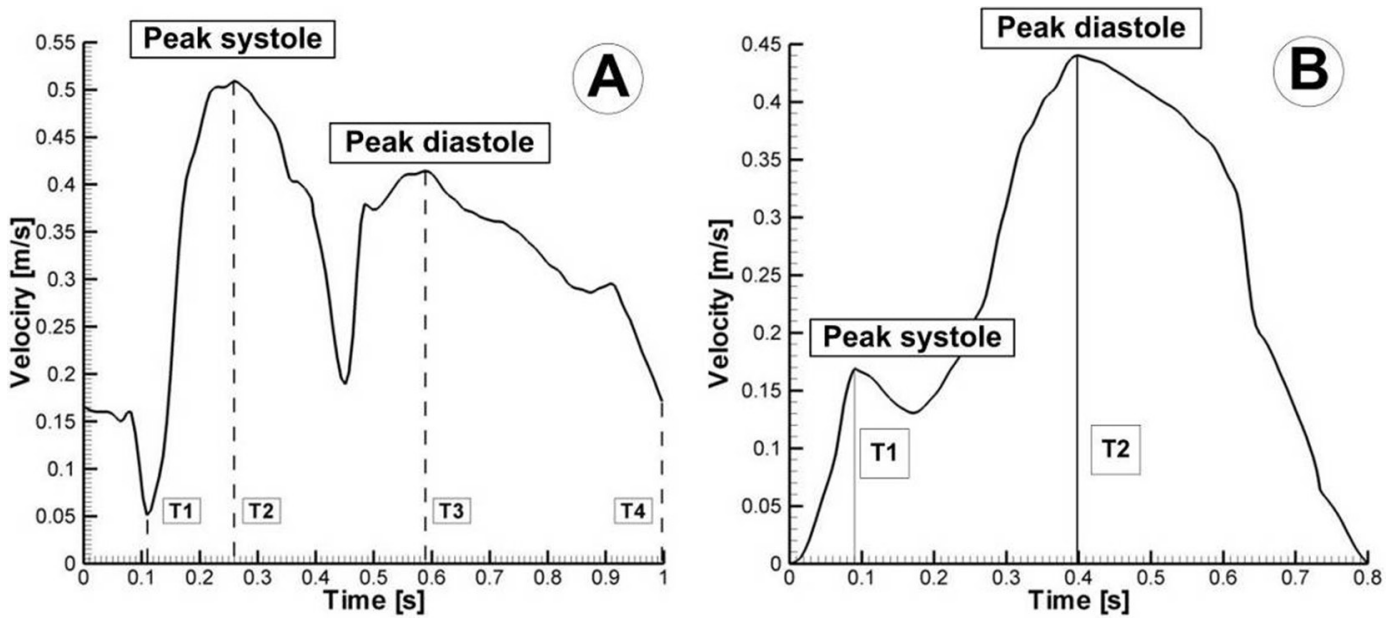

Figure 3: Inlet flow condition. (A) Physiologically realistic velocity waveform based on flow waveforms acquired with an intravascular ultrasound Doppler probe in the RCA, predominant systolic pattern; (B) Inlet velocity waveform used for code validation [29], predominant diastolic pattern.

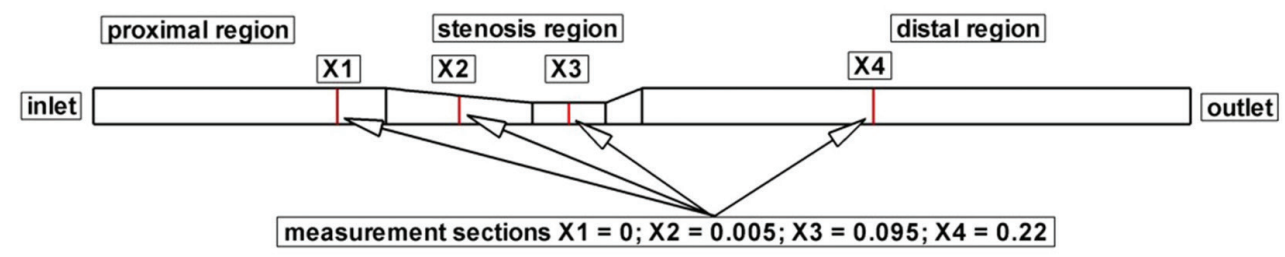

Figure 4: Computational geometry used for our numerical techniques validation [29].

Bellevue, WA) software (Version 10.0) was used for the visualization and quantification of the flow patterns.

\subsection{Code validation}

We validate our numerical techniques by simulating the unsteady flow in axisymmetric moderate stenosis and comparing the results with the solution available in the literature [29]. The geometry model has a stenosis length of ten times the arterial radius ( $\mathrm{Rp}=\mathrm{Rd}=3 \mathrm{~mm}$, see Fig. 4$)$ and a diameter reduction of $40 \%$ (64\% area reduction). The calculations were done at the mean flow rate $\mathrm{Q}=50 \mathrm{ml} / \mathrm{min}$ (typical of basal physiological values in a coronary vessel of $3 \mathrm{~mm}$ size [29]). Heart rate was 75 beats $/ \mathrm{min}$ and blood density was $1050 \mathrm{~kg} / \mathrm{m}^{3}$ [29].

The evolution of the velocity profile in different sections of the stenosis is compared to the experimental data presented by Banerjee et al. [29], as shown in Fig. 5. It can be seen that the present numerical result is in good correlation with the experimental data obtained by Banerjee et al.

\section{RESULTS}

In the present study, the flow characteristics through the serial stenosis were investigated (velocity and pressure field, recirculation regions, and clinically important parameters like FFR). 

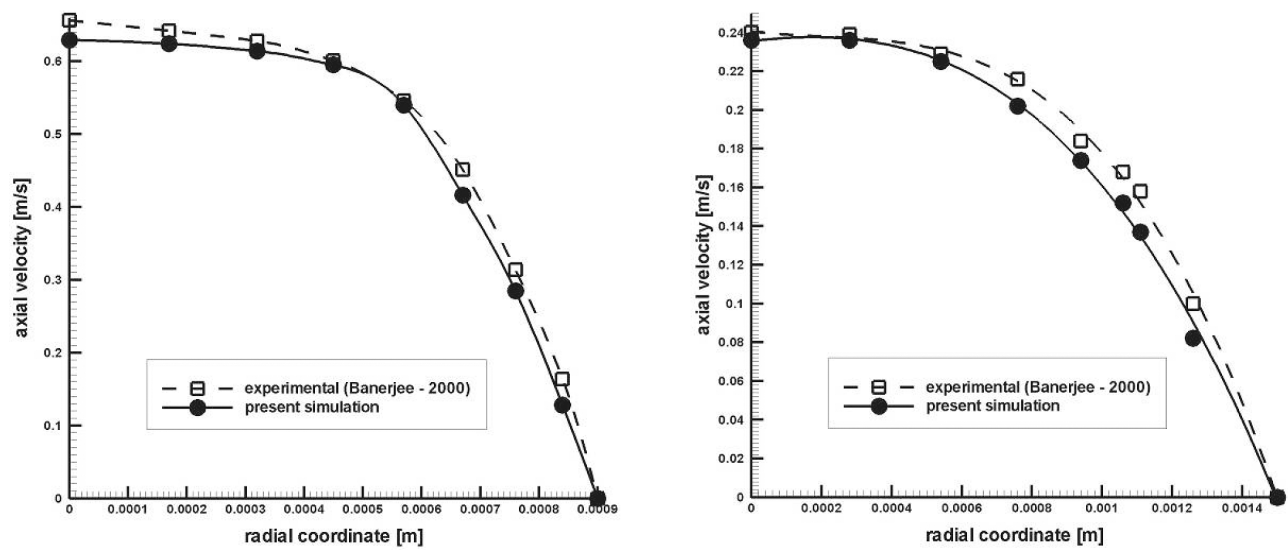

Figure 5: Velocity profile along the stenosis during the cardiac cycle for mean flow rate $\mathrm{Q}=50 \mathrm{ml} / \mathrm{min}$. Comparison between our numerical results and experimental data [29]. Velocity profile at locations: (a) X1 = 0,095 [m] and (b) X2 =0,22 [m]).

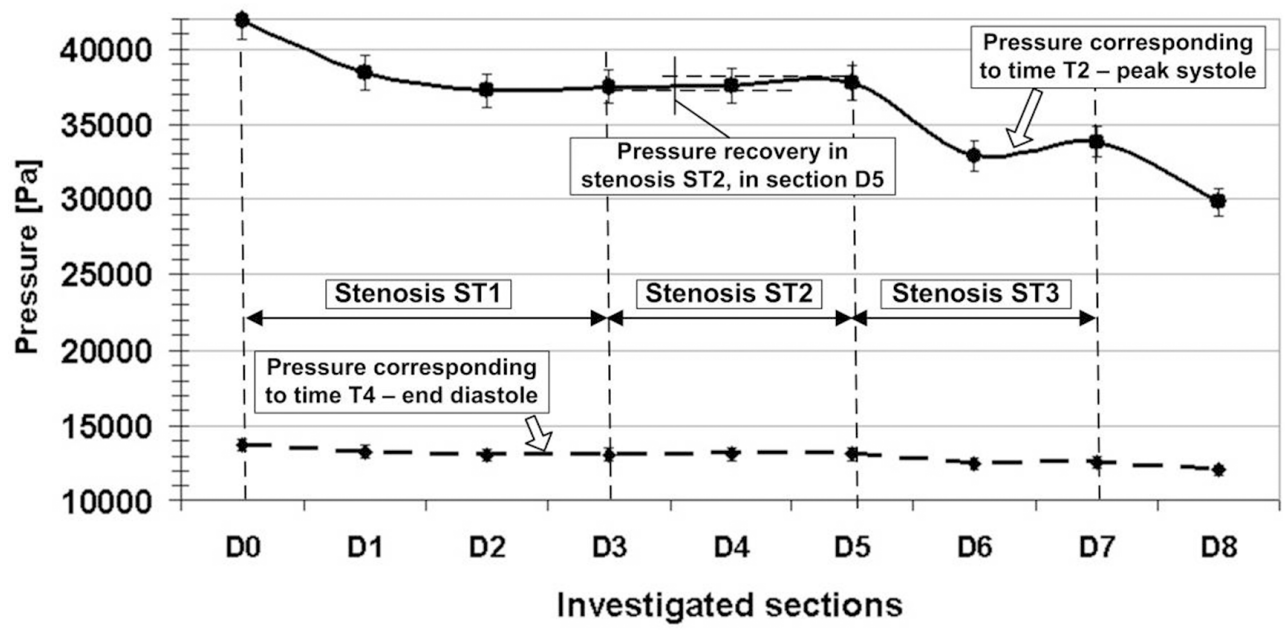

Figure 6: Pressure drop across the investigated multiple stenosed RCA.

\subsection{Pressure distribution}

The pressure distributions along the axial direction for the stenosed RCA are shown in Fig. 6. The pressure drop increases with the increase of percentage stenosis. In stenosis ST1 and ST3, the pressure drop is significant during the systolic phase (Time T2 $=0.26 \mathrm{~s}$ ), while during the diastolic phase at the time T4 = $1 \mathrm{~s}$ the pressure drop across the stenoses ST1 and ST3 is lower. For the stenosis ST2, the pressure drop across the stenosis is lower during the peak systolic phase and is practically negligible during the diastolic phase (Table 3 ).

Overall pressure drop increased appreciably with flow rate (at the peak systole, Fig. 6). Values of the overall pressure drop increased from $300 \mathrm{~Pa}$ at the time T4 to $11000 \mathrm{~Pa}$ at the time T2 (Fig. 6). 
Table 3: Artery flow parameters in the investigated stenosis.

\begin{tabular}{lccccc}
\hline Stenosis & Time & Q $[1 / \mathrm{min}]$ & $\Delta \mathrm{P}[\mathrm{mmHg}]$ & $\mathrm{WSS}_{\max }[\mathrm{Pa}]$ & $\mathrm{WSS}_{\min }[\mathrm{Pa}]$ \\
\hline ST1 & T2 & 0.351 & 32.84 & 210 & 10 \\
& T6 & 0.113 & 4.62 & 45 & 20 \\
ST2 & T2 & 0.37 & 1.46 & 110 & 10 \\
& T6 & 0.118 & 0.03 & 20 & 10 \\
ST3 & T2 & 0.35 & 36.78 & 250 & 10 \\
& T6 & 0.112 & 4.81 & 50 & 10 \\
\hline
\end{tabular}
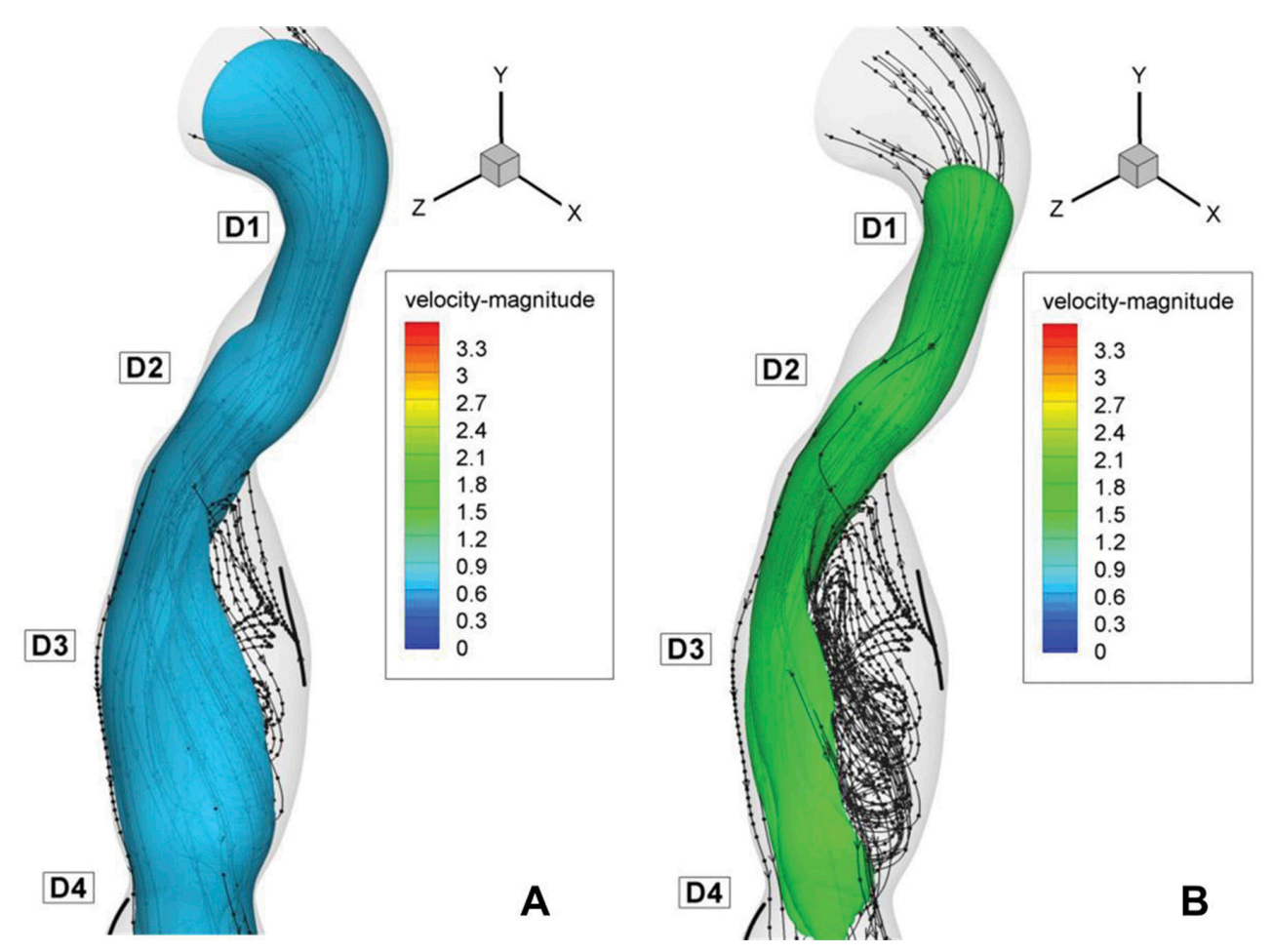

Figure 7: Disturbed flow indicators at the time $\mathrm{T} 2=0.26[\mathrm{~s}]$. (A) Velocity isocontour for blood velocity $\mathrm{v}=0.3[\mathrm{~m} / \mathrm{s}]$; (B) Streamline and velocity isocontour for blood velocity $\mathrm{v}=2[\mathrm{~m} / \mathrm{s}]$ downstream to the stenosis ST1.

The increased pressure drop in the stenoses reflects the increased energy needed to drive the flow through these regions.

Energy loss associated with such flow expansion after each constriction will be large, and consequently the pressure drop will be higher (Fig. 6). The pressure drop associated with spacing between sections D2 and D3, D6 and D7 during the peak flow (time T2) may be attributed to the greater energy loss associated with intense recirculation zones and associated vortex shedding downstream to the stenosis ST1 and ST3 (Fig. 7). 
In hydraulic terms, the pressure drop over the stenosis may arise from pressure losses due to the higher residual stenosis, or pressure losses due to flow turbulence distal to the stenoses [5]. As can be seen in Fig. 6, severe stenosis caused considerably large pressure drop across the throat.

\section{DISCUSSION}

\subsection{Flow separation and secondary flow}

Coronary flow velocity is measurable in numerical simulation and can provide a graphic demonstration of the changes in coronary flow over time and in response to different stimuli (Fig. 8).

The flow separation regions can be seen from the instantaneous velocity field panels which are illustrated in Fig. 9 (stenosis ST1 and ST3). One can observe the pattern of the velocity vector indicated the recirculation zones and the formation of the eddy at the downstream couple of stenoses.

From these figures, it can be observed that the recirculation is formed downstream of each stenosis. There exists a separation streamline that divides the flow into two regimes one which is the recirculating region distal to each stenosis, and the other is the main flow field carrying the bulk of the flow near the centre of the tube.

Development of the recirculation zone downstream to the each constriction is restricted by the next stenosis [5].

The peak velocities value from the current simulations is compared with in vivo measured data by Di Mario et al. [32].

The results of our simulation show that the peak velocity at the throat of the stenosis ST2 is about $1.165 \mathrm{~m} / \mathrm{s}$ (in $28 \%$ diameter reduction stenosis), at the throat of the stenosis ST1 is $2.27 \mathrm{~m} / \mathrm{s}$

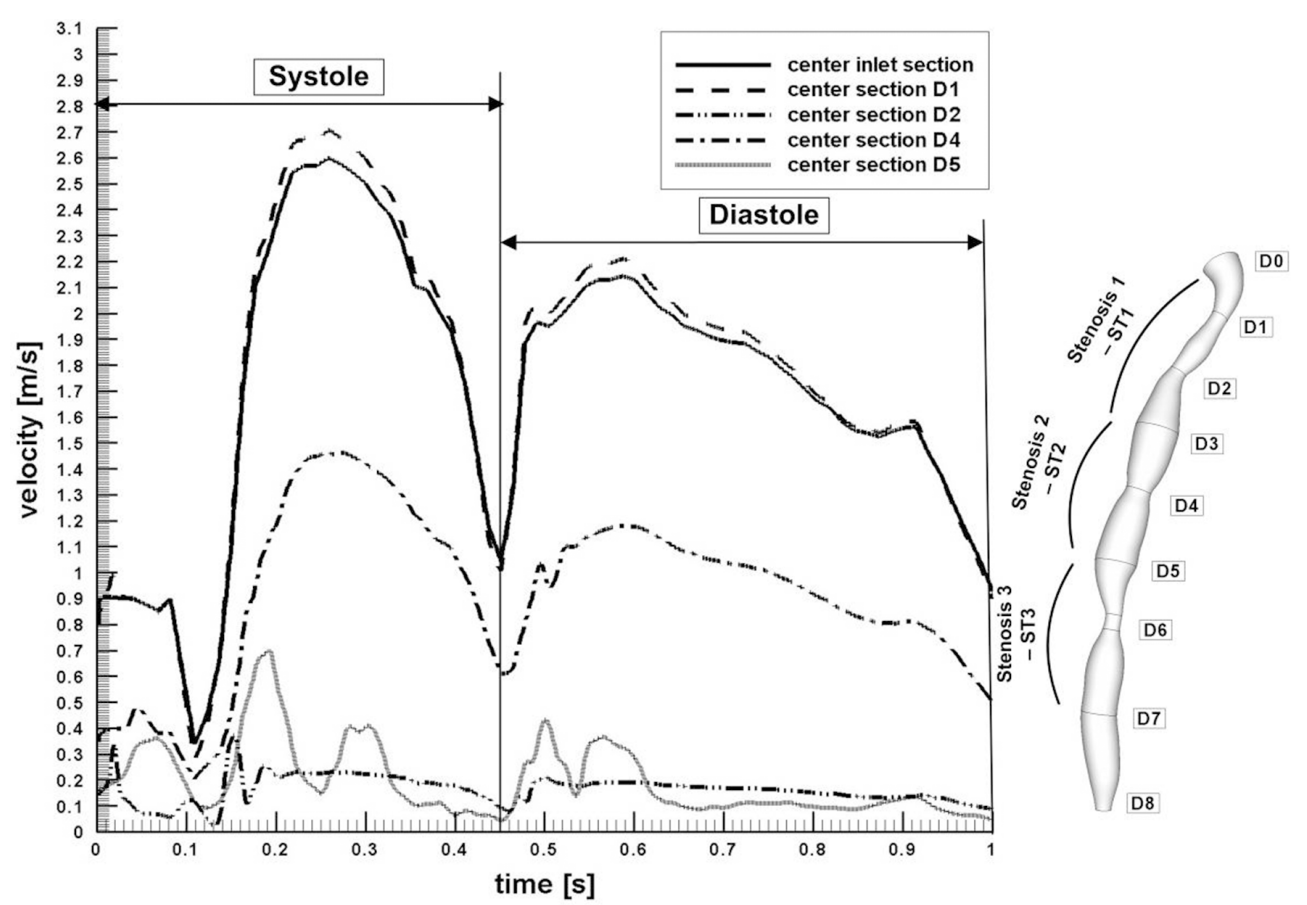

Figure 8: Velocity evolution for different investigated sections during the cardiac cycle. 


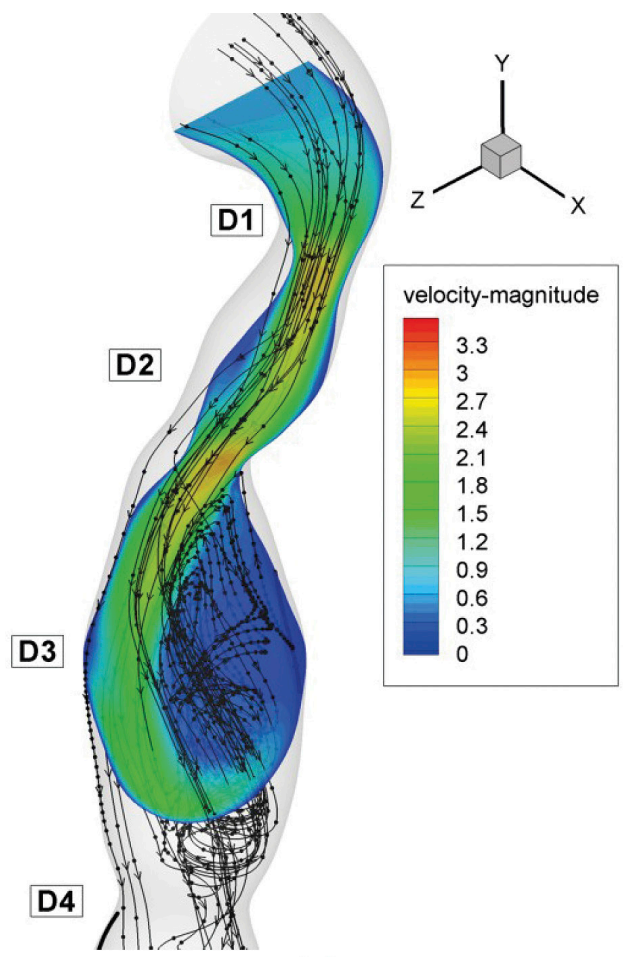

(a)

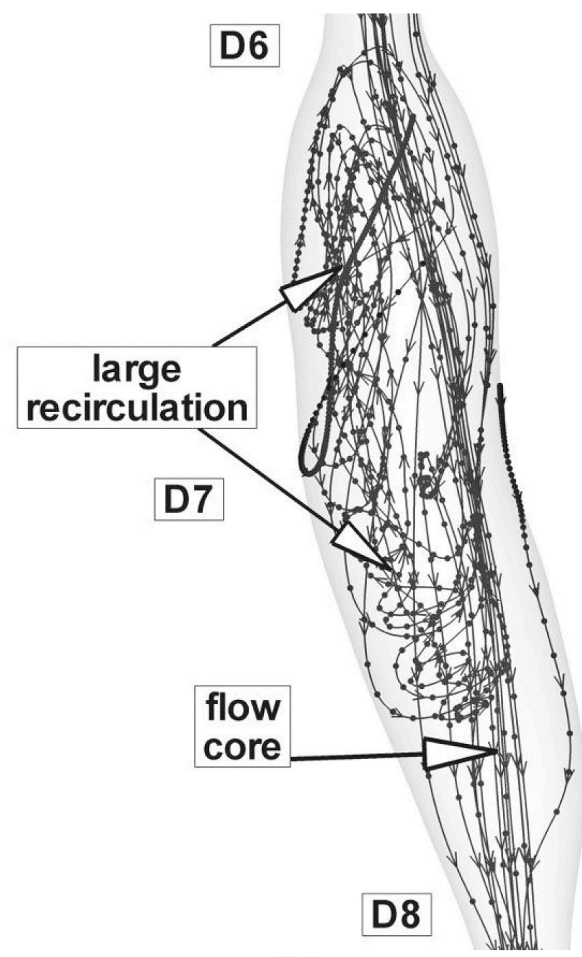

(b)

Figure 9: Disturbed flow indicators at the peak systole T2 $=0.26$ [s]. (a) Stenosis ST1; (b) Stenosis ST3.

(in $53 \%$ diameter reduction stenosis) against a value of $0.78 \mathrm{~m} / \mathrm{s}$ in healthy arteries (Table 4). From the Table 4 result it is clear that our result was in good agreement with both the experimentally measured data by Li et al. [33] and in vivo measured data by Di Mario et al. [32], and Siebes et al. [34].

At the peak flow rate, the Reynolds numbers at the narrowest points in 28\%, 53\%, and 54\% stenoses (stenosis ST2, ST1, and ST3) are about 865, 1141, and 1118, respectively. In the stenosis ST3, the maximum Reynolds number at the throat decreased because of the decrease of flow rate. Downstream of stenosis, flow might become transitional because of the sudden expansion and strong recirculation (sections D3 and D7, Fig. 9).

Figures 7 and 9 show that the post-stenotic deceleration of blood flow induces flow separation and recirculation zones [5]. Such regions of flow separation are favored sites for the development of thrombosis and atherosclerosis [35].

\subsection{Intimal thickening and wall shear stress}

In the case of post stenotic regions, the areas of low wall shear stress are associated with flow separation (Figs 10 and 11). This may be important because it has been suggested that the fluctuation of the wall shear stress or disturbed flow leads to increased endothelial cell turnover and wall thickening. Importantly, in vivo study has shown that the post stenotic region of subcritical stenoses, for example, less than $60 \%$, is associated with increased intimal thickening [36]. If the blood flow is 
Table 4: Comparison of our results with experimental and in vivo data from the literature.

\begin{tabular}{lccccc}
\hline & \multicolumn{2}{c}{ Present study } & & \multicolumn{2}{c}{ In vivo data } \\
\cline { 2 - 3 } \cline { 5 - 6 } Hemodynamic characteristics & $\%$ DS & Value & & $\%$ DS & Value \\
\hline Peak velocity $[\mathrm{m} / \mathrm{s}]$ & $28 \%-\mathrm{ST} 2$ & 1.165 & - & - \\
& $53 \%-\mathrm{ST} 1$ & 2.27 & & $169.1 \pm 4.8 \%$ & $2.1 \pm 2.8$ \\
Reynolds number in the throat $[-]$ & $28 \%-\mathrm{ST} 2$ & 865 & & - & - \\
& $53 \%-\mathrm{ST} 1$ & 1141 & & $174.3 \pm 3.7 \%$ & 957 \\
Peak WSS $[\mathrm{Pa}]$ & $28 \%-\mathrm{ST} 2$ & 110 & & - & - \\
Pressure drop $[\mathrm{mmHg}]$ & $53 \%-\mathrm{ST} 1$ & 210 & & $169.1 \pm 4.8 \%$ & 184 \\
& $28 \%-\mathrm{ST} 2$ & 0.03 & & - & - \\
& $53 \%-\mathrm{ST} 1$ & 32.84 & & $252.2 \pm 8.6 \%$ & $36.9 \pm 17.3$ \\
\hline
\end{tabular}

$\%$ DS percent diameter stenosis; * pressure drop from the inlet to the throat; ${ }^{1}$ Di Mario et al. [31]; ${ }^{2}$ Siebes et al. [33].

increased, that increases wall shear stress, an adaptive increase in arterial luminal size is observed. If the blood flow is decreased, usually by a proximal stenosis, that decreases the wall shear stress, and there is an adaptive decrease in arterial lumen size [37].

In Figs 10 and 11, shear stress distribution was shown around the investigated stenoses. The point, where the maximum shear stress occurs, lies at the narrowest cross-section D4 for stenosis ST2 and section D6 for stenosis ST3. In Fig. 10A, the separation region at the time T2 occurs at the downstream of the stenosis ST1 and ST2 in sections D3 and D5. There is a rapid increase in wall shear stress upstream of the first stenosis, then after the critical height of stenosis (section D2 and D4), the wall shear stress decreases until separation occurs.

Figure 10B shows wall shear stress (WSS) distribution at the time $\mathrm{T} 2=0.26 \mathrm{~s}$, the time where the flow is at a maximum (peak systole). The range of WSS in this figure varies from 5 to $234 \mathrm{~Pa}$ as opposed to 5 to $45 \mathrm{~Pa}$ at the time T4 $=1 \mathrm{~s}$ (Fig. 11B). Three intense regions of low WSS appear downstream at each stenosis (Figs 10B and 11B). For these regions the WSS is approximately $5 \mathrm{~Pa}$. On the opposite side of this regions we have the regions of moderate and high WSS (WSS varies from 15 to $90 \mathrm{~Pa}$ at the time $\mathrm{T} 2$ and from 15 to $30 \mathrm{~Pa}$ at the time T4).

As the flow decelerates, the regions with a high WSS and more zone of moderate and low WSS begin to appear (Time T4, Fig. 11B).

The location of the WSS peaks agrees well with clinical observations of elevated mass transfer in stenoses, i.e. mass transfer occurs on the fore and sides of the occlusion and not in the throat [38].

Our study shows that the peak WSS reached $110 \mathrm{~Pa}$ at the throat of the stenosis ST2 (28\% diameter reduction), which is high enough to damage the endothelial cells. Both, high wall shear and stagnant flow regions have been identified as favorable conditions for platelet aggregation through inherently different pathways [39].

\section{CLINICAL SIGNIFICANCE}

\subsection{Translesional hemodynamic variables}

Clinically important stenoses can be characterized by: proximal/distal flow ratio, diastolic/systolic velocity ratio, and distal coronary vasodilator reserve (defined as hyperemia/basal mean flow ratio). 


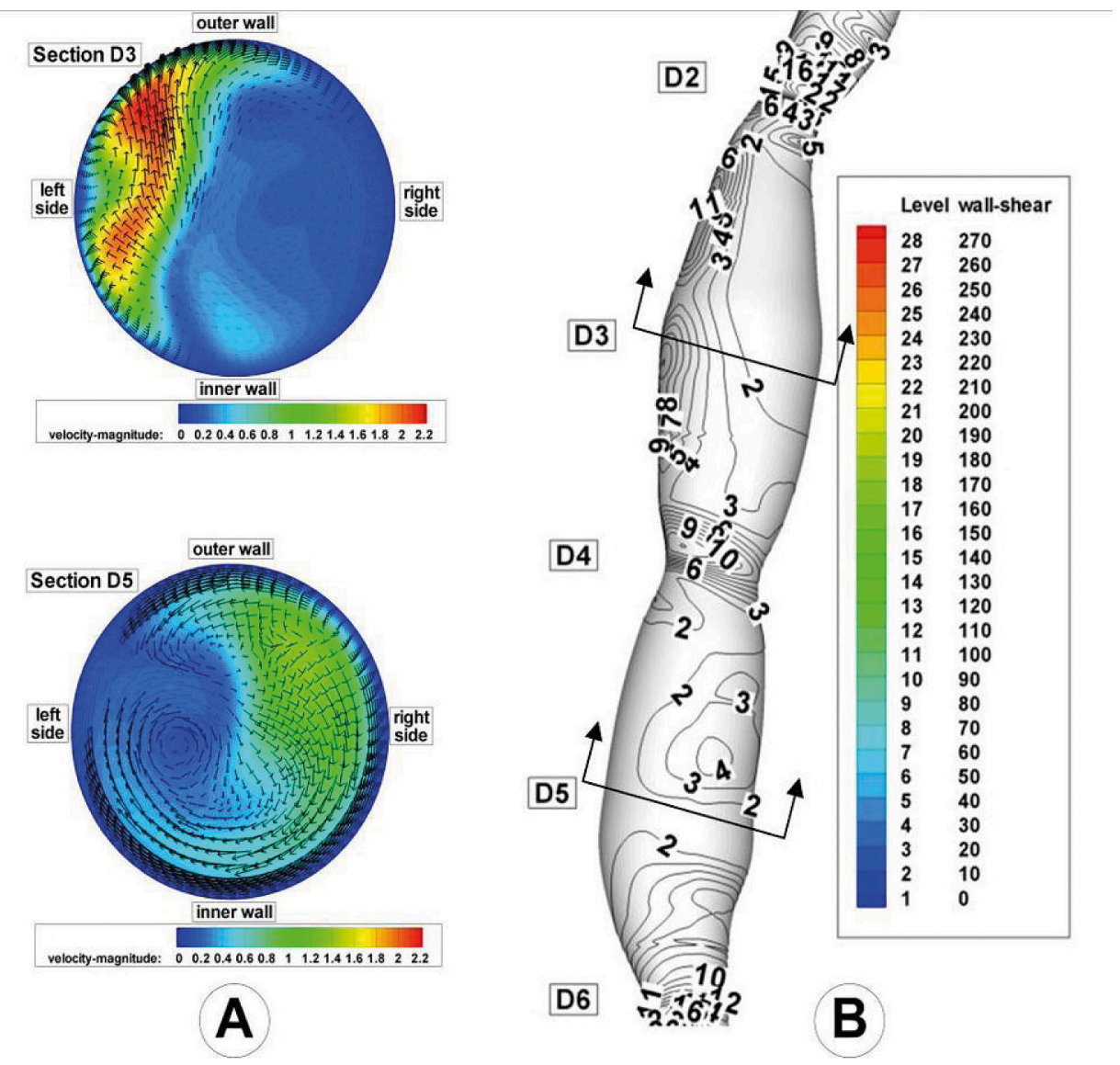

Figure 10: Disturbed flow indicators at the peak systole T2 $=0.26$ [s]. (A) Cross-sectional transient velocity vector fields; (B) Temporal WSS magnitude contours in stenosis ST1 and ST2 (WSS value are in $[\mathrm{Pa}]$ ).

The correlations of the percent stenosis with translesional pressure gradients are presented in Fig. 12A. Correlations of the percent stenosis with fractional flow reserve are presented in Fig. 12B. For a series of two stenoses, the corresponding pressure gradients is around $30 \mathrm{mmHg}$ (Fig. 10A). As shown in Fig. 10B, stenosis with FFR < 0.7, is associated to the severe stenosis (\% stenosis $>70 \%$ ).

In the previous studies, Donohue et al. [40] concluded that within branching coronary circulations, translesional flow velocity ratios $<1.7$ are associated with translesional pressure gradients $<30 \mathrm{mmHg}$.

\subsection{Fractional flow reserve (FFR)}

FFR has become important to understand when a stenosis is significant to cause myocardial ischemia and warrant coronary intervention.

Fractional flow reserve (FFR), can be expressed as a maximum achievable myocardial blood flow in the presence of a coronary artery stenosis $[14,41]$. FFR is conventionally calculated as the ratio of the pressure distal $(\mathrm{Pd})$ and proximal $(\mathrm{Pa})$ to the stenosis $(\mathrm{FFR}=\mathrm{Pd} / \mathrm{Pa})$. In this formula, $\mathrm{Pd}$ is the pressure distal to the stenosis, and $\mathrm{Pa}$ is the aortic pressure. 

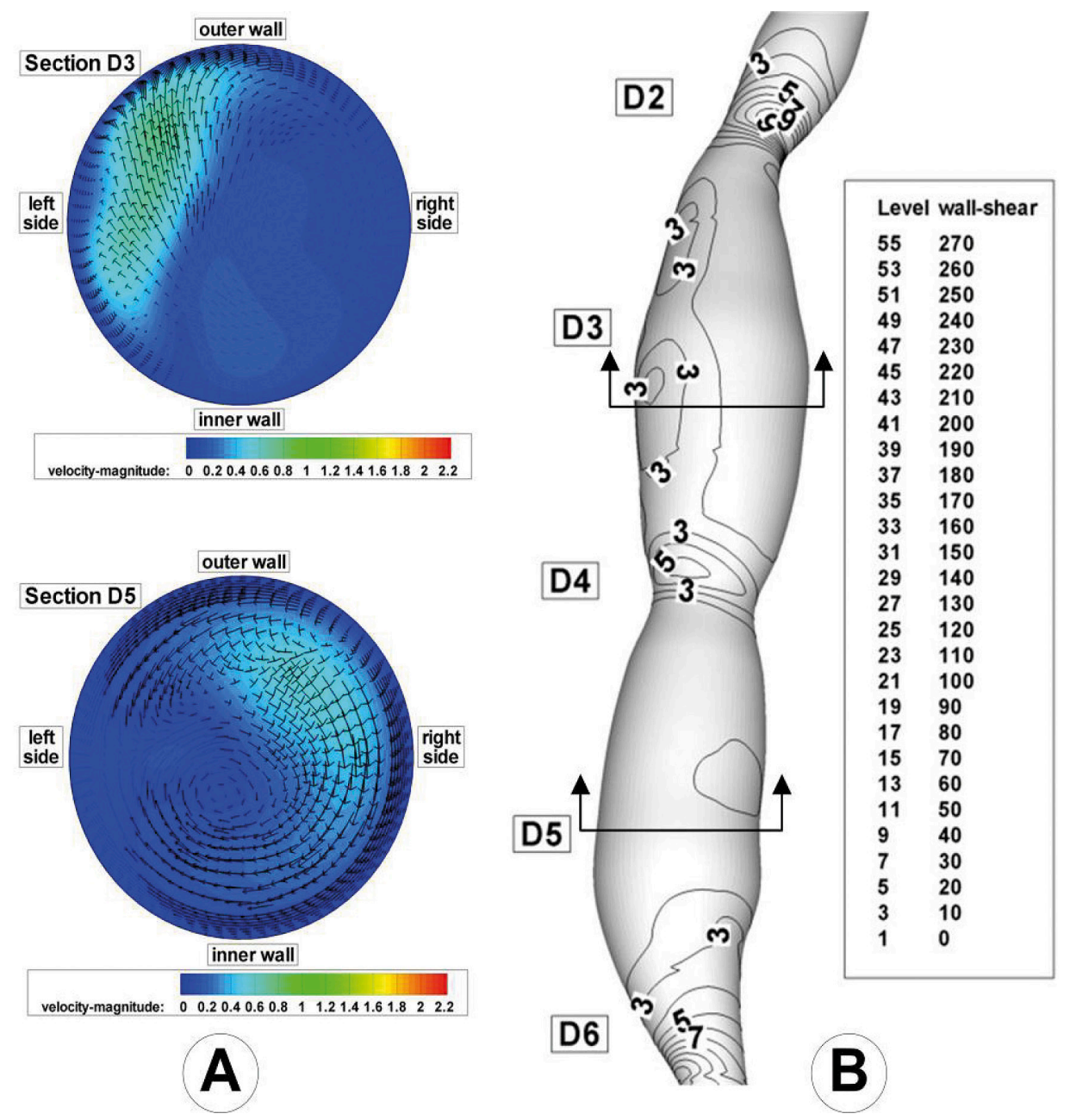

Figure 11: Disturbed flow indicators at the end of diastole $\mathrm{T} 4=1$ [s]. (A) Cross-sectional transient velocity vector fields; (B) Temporal WSS magnitude contours in stenosis ST1 and ST2 (WSS value are in $[\mathrm{Pa}]$ ).

In clinical practice, FFR is useful to assess the severity of a coronary stenosis and to decide whether or not to do an intervention. A threshold value of 0.75 is used in the literature to distinguish between the significant and a non-significant stenosis [42, 43].

Figure 13 shows a comparison between hemodynamic variables obtained numerically in the present study using the CFD technique and values obtained in vitro study for the same patient. We can see that the results of the numerical investigation correlate well with the in vitro measured parameters.

\subsection{Study limitations}

First, we modeled only the trunk of the RCA, ignoring all its branches. Second, in this model, vessel walls are assumed rigid, results might differ in elastic models of the coronary artery wall. 

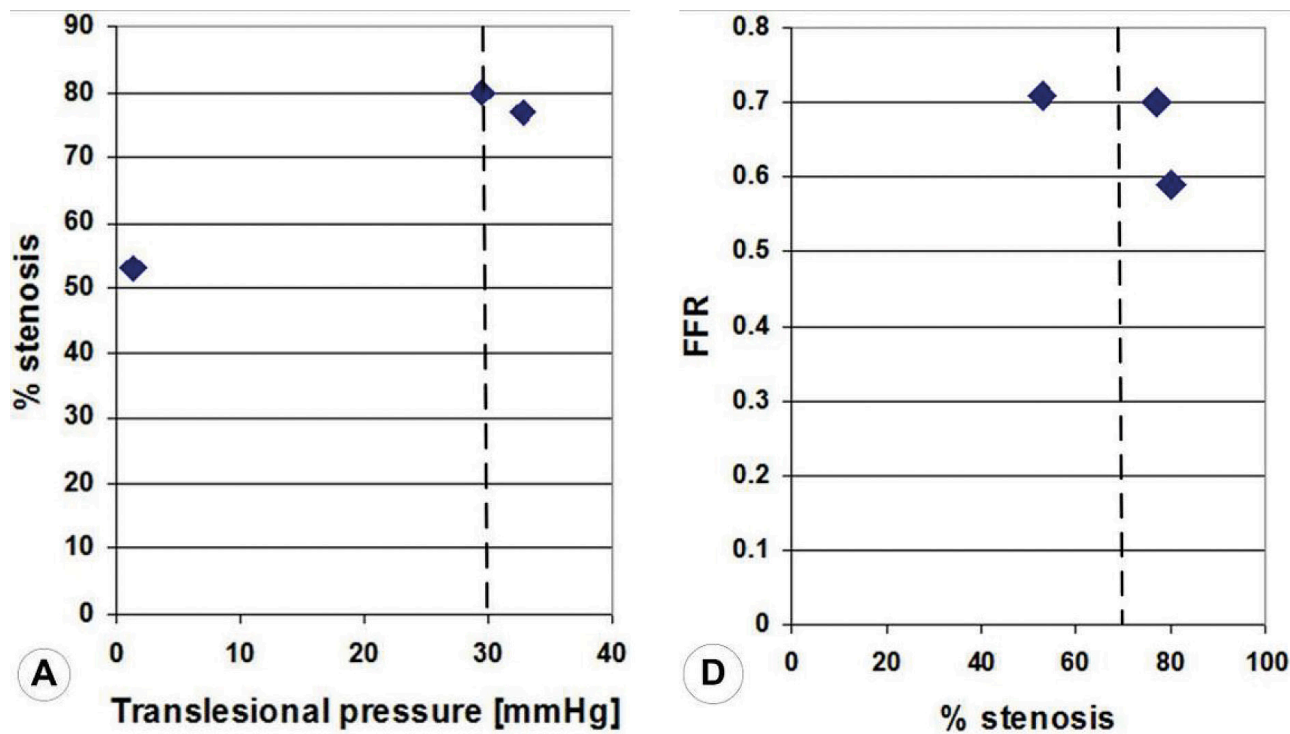

Figure 12: (A) Percent diameter stenosis correlation with translesional pressure gradient; (B) Percent diameter stenosis correlation with fractional flow reserve (FFR).
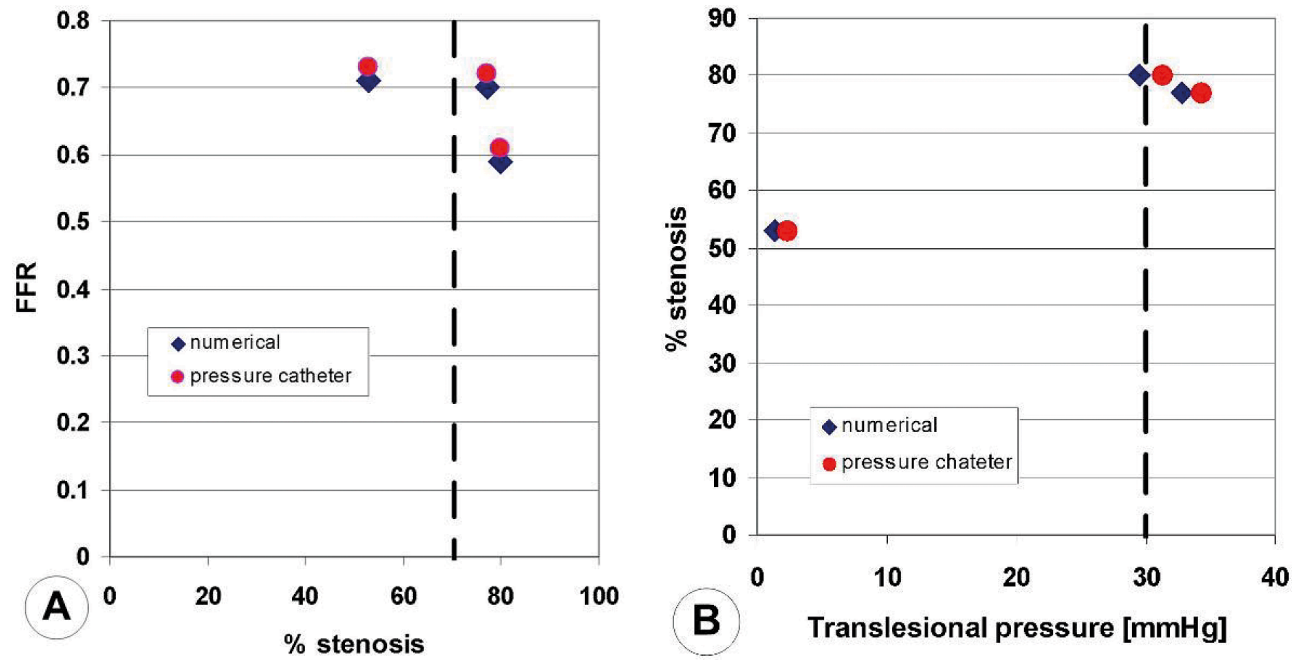

Figure 13: Comparison between translesional hemodynamic variables obtained numerically and during intervention. (A) Percent area stenosis correlation with fractional flow reserve (FFR); (B) Stenosis area correlation with translesional pressure gradient.

Zeng et al. [44] have incorporated the effects of physiologically realistic arterial motion into a simulation of blood flow patterns in the RCA. The results show that the arterial motion had little effect on the WSS distribution within the RCA and that flow in the moving artery followed the instantaneous dynamic geometry quite closely. These results agree with the findings of other groups [45]. 


\section{CONCLUSIONS}

The results of maximum blood velocities from this study agree well with published clinical measurement, indicating that the model used is physiologically realistic. Results in different degrees of stenoses show that severe stenosis caused considerably large pressure drop across the throat.

We can conclude that:

- CFD techniques, on the other hand, can provide a significantly larger amount of information on coronary flow dynamics, with greater spatial and temporal resolution, noninvasively, on a patient-specific basis and within a completely virtual environment;

- local hemodynamic factors are crucial to determining the evolution of coronary obstructions (in accordance with Figs 6 and 9);

- taking into account that the trans-stenotic pressure drop is inversely proportional to the fourth power of the lumen diameter, in a middle, and severe stenosis, relatively small change in luminal diameter can produce marked hemodynamic effects;

- the parameters that govern the unsteady flow dynamics in a vessel with multiple constrictions are Reynolds' number, degree of stenosis, and the spacing between the stenosis;

- the main feature of the flow field, is the separation and reattachment of the flow distal to the stenosis;

- blood flow in distal part of the stenosis, are associated with large spatial fluctuations of the wall shear stress and velocity;

- the instantaneous streamlines of the physiological flow show a considerable variation throughout the cycle, characterized by the formation of a vortex just downstream of the stenosis zone during the accelerating phase (during the systole);

- the recirculation length increases as the flow accelerates (during the systole).

Taking into account the complexity of the fluid dynamic behavior in the multiple sequential stenoses, the stenoses severity cannot be adequately assessed only by visual interpretation of the coronary angiogram. Analysis of FFR adds important functional and anatomic information regarding the luminal augmentation of the blood vessel. Both, FFR analysis and CFD technique can help medical staff to identify intermediate lesions of the coronary artery and reduce potential complications of the coronary angiogram visual interpretation.

\section{REFERENCES}

[1] Bluestein, D., Gutierrez, C., Londono, M. \& Schoephoerster M., Vortex shedding in steady flow through a model of an arterial stenosis and its relevance to mural platelet deposition. Annals of Biomedical Engineering, 27, pp. 763-773, 1999. doi: http://dx.doi.org/10.1114/1.230

[2] Stroud, J., Berger, S. \& Saloner, D., Influence of stenosis morphology on flow through severely stenotic vessels: implications for plaque rupture. Journal of Biomechanics, 33, pp. 443-455, 2000. doi: http://dx.doi.org/10.1016/s0021-9290(99)00207-9

[3] Morton, J.K., Curriculum in Interventional Cardiology: Coronary Pressure and Flow Measurements in the Cardiac Catheterization Laboratory. Catheterization and Cardiovascular Interventions, 54, pp. 378-400, 2001. doi: http://dx.doi.org/10.1002/ccd.1303

[4] Bernhard, S., Transient integral boundary layer method to simulate entrance flow conditions in one-dimensional arterial blood flow, PhD Thesis, 2006, http://ediss.uni-goettingen.de/ handle/11858/00-1735-0000-0006-B443-0?show=full\&locale-attribute=en.

[5] Bernhard S., Möhlenkamp S. \& Tilgner, A., Transient integral boundary layer method to calculate the translesional pressure drop and the fractional flow reserve in myocardial bridges, BioMedical Engineering OnLine, 5(42), 2006. doi: http://dx.doi.org/10.1186/1475-925x-5-42 
[6] Marques, K.M.J. \& Westerhof, N., Characteristics of the flow velocity-pressure gradient relation in the assessment of stenoses: an in vitro study. Netherlands Heart Journal, 16, pp. 156-162, 2008. doi: http://dx.doi.org/10.1007/bf03086137

[7] Kang1, M.J., Ji, H-S. \& Lee S.J., In-vitro study on haemodiluted blood flow in a sinusoidal microstenosis. Proc. ImechE Part H: J. Engineering in Medicine, 224, pp. 17-25, 2010. doi: http://dx.doi.org/10.1243/09544119jeim644

[8] Younis, B.A. \& Berger, S.A., A turbulence model for pulsatile arterial flows. Journal of Biomechanical Engineering, 126, pp. 578-584, 2004. doi: http://dx.doi.org/10.1115/1.1798032

[9] Damodaran, V., Rankin, G.W. \& Zhang, Z., Numerical study of steady laminar flow through tubes with multiple constrictions using curvilinear co-ordinates. International Journal for Numerical Methods in Fluids, 23, pp. 1021-1041, 1996. doi: http://dx.doi.org/10.1002/ (sici)1097-0363(19961130)23:10<1021::aid-fld449>3.0.co;2-d

[10] Johnston, B.M., Johnston, P.R., Corney, S. \& Kilpatrick, D., Non-Newtonian blood flow in human right coronary arteries: transient simulations. Journal of Biomechanics, 39, pp. 1116-1128, 2005. doi: http://dx.doi.org/10.1016/j.jbiomech.2005.01.034

[11] Sabbah, H.N. \& Stein, P.D., Hemodynamics of multiple versus single 50 percent coronary arterial stenoses. American Journal of Cardiology, 50, pp. 276-280, 1982. doi: http://dx.doi. org/10.1016/0002-9149(82)90177-1

[12] Johnston, P.R. \& Kilpatrick, D., Mathematical modeling of paired arterial stenoses, Proceeding Computers in Cardiology, pp. 229-232, 1990. doi: http://dx.doi.org/10.1109/cic.1990.144202

[13] Bernad S.I., Totorean A., Bernad E.S. \& Susan-Resiga R., Particle motion in coronary serial stenoses, WIT Transaction on Biomedicine and Health, 17, WIT Press, 2013, ISSN: 1743-3525, doi: http://dx.doi.org/10.2495/bio130151

[14] Bertolotti, C., Qin, Z., Lamontagne, B., Durand, L-G., Soulez, G. \& Cloutier G., Influence of multiple stenoses on echo-Doppler functional diagnosis of peripheral arterial disease: a numerical and experimental study. Annals of Biomedical Engineering, 34, pp. 564-574, 2006. doi: http://dx.doi.org/10.1007/s10439-005-9071-7

[15] Pijls, N.H.J., De Bruyne, B., Jan Willem Bech, G., Liistro, F., Heyndrickx, GR, Bonnier, H.J.R.M. \& Koolen J.J., Coronary pressure measurement to assess the hemodynamic significance of serial stenoses within one coronary artery: validation in humans. Circulation, 102, pp. 2371-2377, 2000. doi: http://dx.doi.org/10.1161/01.cir.102.19.2371

[16] Bernad, S.I., Bernad, E., Barbat, T., Albulescu, V. \& Susan-Resiga, R., Effects of different types of input waveforms in patient-specific right coronary atherosclerosis hemodynamics analysis. International Journal of Design \& Nature and Ecodynamics, 5(2), pp. 1-18, 2010. doi: http://dx.doi.org/10.2495/dne-v5-n2-142-159

[17] Dodds, S.R., The haemodynamics of asymmetric stenoses. European Journal of Vascular Endovascular Surgery, 24, pp. 332-337, 2002. doi: http://dx.doi.org/10.1053/ejvs.2002.1729

[18] Liu, B., The influences of stenosis on the downstream flow pattern in curved arteries. Medical Enginnering \& Physics, 29, pp. 868-876, 2007. doi: http://dx.doi.org/10.1016/j.medengphy.2006.09.009

[19] Staikov, I.N., Arnold, M., Mattle, H.P., Remonda, L., Sturzenegger, M., Baumgartner, R.W. \& Schroth, G., Comparison of the ECST, CC, and NASCET grading methods and ultrasound for assessing carotid stenosis. Journal of Neurology, 247, pp. 681-686, 2000. doi: http://dx.doi. org/10.1007/s004150070110

[20] Rothwell, P.M., Eliasziw, M., Gutnikov, S.A., Fox, A.J., Taylor, D.W., Mayberg, M.R., Warlow, C.P., Barnett, H.J.; Carotid Endarterectomy Trialists' Collaboration, Analysis of pooled data from the randomized controlled trials of endarterectomy for symptomatic carotid stenosis. Lancet, 361, pp. 107-16, 2003. doi: http://dx.doi.org/10.1016/s0140-6736(03)12228-3 
[21] FLUENT 6.3 User's Guide 2006. Ansys Fluent Incorporated.

[22] Mohammadi, B., 3D Analysis of blood flow in consecutive stenoses of coronary artery. Journal of Basic and Applied Scientific Research, 2(7), pp. 6730-6739, 2012. doi: http://dx.doi. org/10.1161/01.cir.90.6.3123

[23] Banerjee, M.K., Ganguly, R. \& Datta, A., Effect of pulsatile flow waveform and womersley number on the flow in stenosed arterial geometry. ISRN Biomathematics, Article ID 853056, 17 pages, 2012. doi: http://dx.doi.org/10.5402/2012/853056

[24] Molla, M.M. \& Paul, M.C., LES of non-Newtonian physiological blood flow in a model of arterial stenosis. Medical Engineering and Physics, 34 (8), pp. 1079-1087, 2012. doi: http:// dx.doi.org/10.1016/j.medengphy.2011.11.013

[25] Ghalichi, F. \& Deng, X., Turbulence detection in a stenosed artery bifurcation by numerical simulation of pulsatile blood flow using the low-Reynolds number turbulence model. Biorheology, 40, pp. 637-654, 2003.

[26] Mittal, R., Simmons, S.P. \& Udaykumar, H.S., Application of large-eddy simulation to the study of pulsatile flow in a modeled arterial stenosis. Journal of Biomechanical Engineering, 123, pp. 325-332, 2001. doi: http://dx.doi.org/10.1115/1.1385840

[27] Rayz, V.T., Berger, S.A. \& Salomer, D., Transitional flow in arterial fluid dynamics. Computer Methods in Applied Mechanics and Engineering, 196, pp. 3043-3048, 2007. doi: http://dx.doi. org/10.1016/j.cma.2006.10.014

[28] Tan, F.P.P., Soloperto, G., Bashford, S., Wood, H.B., Thom, S., Hughes, A. \& Xu, X.Y., Analysis of flow disturbance in a stenosed carotid artery bifurcation using two-equation transitional and turbulence models. Journal of Biomechanical Engineering, 130, 061008-1, 2008. doi: http:// dx.doi.org/10.1115/1.2978992

[29] Banerjee, R.K., Back, L.H., Back, M.R. \& Cho, Y.I., Physiological flow simulation in residual human stenoses after coronary angioplasty. ASME Journal of Biomechanical Engineering, 122, pp. 310-320, 2000. doi: http://dx.doi.org/10.1115/1.1287157

[30] Zeng, D., Boutsianis, E., Ammann, M., Boomsma, K., Wildermuth, S. \& Poulikakos, D., A study of the compliance of a right coronary artery and its impact on wall shear stress. Journal of Biomechanical Engineering, 130, pp. 041014-11, 2008. doi: http://dx.doi.org/10.1115/1.2937744

[31] Torii, R., et al., Differences in coronary artery haemodynamics due to changes in flow and vascular geometry after percutaneous coronary intervention. Heart, 94, pp. A1-A4, 2008.

[32] Di Mario, C., Meneveau, C., Gil, R., Jaegere, P., Feyter, P.J., Slager, C., Roelandt, J.R.T.C. \& Serruys, P.W., Maximal blood flow velocity in severe coronary stenoses measured with a doppler guidewire, Limitations for the application of the continuity equation in the assessment of stenosis severity. American Journal of Cardiology, 71, pp. 54D-61D, 1993. doi: http://dx.doi. org/10.1016/0002-9149(93)90134-х

[33] Li, L.X., Beech-Brandt, J.J., John, L.R., Hoskins, P.R. \& Easson, W.J., Numerical analisys of pulsatile blood flow and vessel wall mechanics in different degrees of stenoses. Journal of Biomechanics, 40, pp. 3715-3724, 2007. doi: http://dx.doi.org/10.1016/j.jbiomech.2007.06.023

[34] Siebes, M., Verhoeff, B-J., Meuwissen, M., de Winter, J., Jos, R., Spaan A.E. \& Piek, J.J., Single-Wire Pressure and Flow Velocity Measurement to Quantify Coronary Stenosis Hemodynamics and Effects of Percutaneous Interventions. Circulation, 109, pp. 756-762, 2004. doi: http://dx.doi.org/10.1161/01.cir.0000112571.06979.b2

[35] Guha, A., Transport and deposition of particles in turbulent, and laminar flow. Annual Review of Fluid Mechanics, 40, pp. 311-341, 2008. doi: http://dx.doi.org/10.1146/annurev.fluid. 40.111406 .102220 
[36] Chatzizisis, Y.S., Coskun, A.U., Jonas, M., Edelman, E.R., Feldman, C.L. \& Stone, P.H., Role of endothelial shear stress in the natural history of coronary atherosclerosis and vascular remodeling, molecular, cellular, and vascular behavior. JACC, 49(25), pp. 2379-93, 2007. doi: http://dx.doi.org/10.1016/j.jacc.2007.02.059

[37] Cheng, C., Tempel, D., van Haperen, R., van der Baan, A., Grosveld, F., Daemen, M.J.A.P., Krams, R. \& Crom, R., Atherosclerotic lesion size and vulnerability are determined by patterns of fluid shear stress. Circulation, 113, pp. 2744-2753, 2006. doi: http://dx.doi.org/10.1161/ circulationaha.106.658302

[38] Sun, N., Wood, N.B., Hughes, A.D., Thom, S.A.M. \& Xu, X.Y., Fluid-wall modelling of mass transfer in an axisymmetric stenosis: effects of shear-dependent transport properties. Annals of Biomedical Engineering, 34(7), pp. 1119-1128, 2006. doi: http://dx.doi.org/10.1007/s10439006-9144-2

[39] Sho, E., Nanjo, H., Sho, M., Kobayashi, M., Komatsu, M., Kawamura, K., Xu, C., Zarins, C.K. \& Masuda, H., Arterial enlargement, tortuosity, and intimal thickening in response to sequential exposure to high and low wall shear stress. Journal of Vascular Surgery, 39, pp. 601-612, 2004. doi: http://dx.doi.org/10.1016/j.jvs.2003.10.058

[40] Donohue, T.J., Kern, M.J., Aguirre, F.V., Bach, R.G., Wolford, T., Bell, C.A., Segal, J., Assessing the hemodynamic significance of coronary artery stenoses: analysis of translesional pressure flow velocity relationships in patients. Journal of the American College of Cardiology, 22, pp. 449-458, 1993. doi: http://dx.doi.org/10.1016/0735-1097(93)90049-7

[41] Kern, M.J., Lerman, A., Bech, J.W., De Bruyne, B., Eeckhout, E., Fearon, W.F., Higano, S.T., Lim, M.J., Meuwissen, M., Piek, J.J., Pijls, N.H.J., Siebes M. \& Spaan, J.A.E., Physiological Assessment of Coronary Artery Disease in the Cardiac Catheterization Laboratory: A Scientific Statement from the American Heart Association Committee on Diagnostic and Interventional Cardiac Catheterization, Council on Clinical Cardiology. Circulation, 114, pp. 1321-1341, 2006. doi: http://dx.doi.org/10.1161/circulationaha.106.177276

[42] Lim, M.J. \& Kern, M.J., Coronary Pathophysiology in the Cardiac Catheterization Laboratory. Current Problems in Cardiology, 31, pp. 493-550, 2006. doi: http://dx.doi.org/10.1016/j. cpcardiol.2006.04.002

[43] Tobis, J., Azarbal, B. \& Slavin, L., Assessment of Intermediate Severity Coronary Lesions in the Catheterization Laboratory. Journal of the American College of Cardiology, 49, pp. 839-848, 2007. doi: http://dx.doi.org/10.1016/j.jacc.2006.10.055

[44] Zeng, D., Ding, Z., Friedman, M.H. \& Ethier, C.R., Effects of cardiac motion on right coronary artery hemodynamics. Annals of Biomedical Engineering, 31, pp. 420-429, 2003. doi: http:// dx.doi.org/10.1114/1.1560631

[45] Qiu, Y. \& Tarbell, J.M., Numerical simulation of pulsatile flow in a compliant curved tube model of a coronary artery. Journal of Biomechanical Engineering, 122, pp. 77-85, 2000. doi: http://dx.doi.org/10.1115/1.429629 